\title{
Identifikasi Jenis Ikan Mudskipper di Pantai Surabaya dan Sidoarjo
}

\author{
Anisya Eka Juniar'), Syefrina Rosyada ${ }^{1)}$, Ahnan Mahfudz Nur S ${ }^{1)}$, Dwi Anggorowati Rahayu ${ }^{1 *}$ \\ 1) Jurusan Biologi, Fakultas Matematika dan Ilmu Pengetahuan Alam, Universitas Negeri Surabaya, Jl. Ketintang Gedung \\ C3, Surabaya, Jawa Timur, Indonesia \\ *) Alamat korespondensi: dwirahayu@unesa.ac.id
}

\begin{abstract}
ABSTRAK
Ikan Mudskipper termasuk dalam Famili Gobiidae yang beradaptasi terhadap dua habitat berbeda. Keberadaan ikan ini sangat melimpah di alam, namun belum banyak masyarakat yang memperhatikan keberadaannya. Tujuan penelitian ini adalah untuk mengidentifikasi spesies ikan Mudskipper yang ditemukan di Pantai Kenjeran, Tambak Mangrove Wonorejo, dan Tambak Sedati sehingga menjadi tambahan informasi terutama tentang aspek taksonomi dan ekologi sebagai dasar pengelolaan dan pemanfaatannya. Metode yang digunakan adalah survei melalui penyisiran lokasi-lokasi pengambilan sampel ikan Mudskipper di tiga lokasi berbeda dan identifikasi menggunakan karakter morfologi yaitu morfometrik, meristrik dan ciri diagnostik penentu spesies. Hasil penelitian ini ditemukan empat spesies ikan Mudskipper dari ketiga lokasi penelitian yaitu Boleophthalmus boddarti, Periopthalmus novemradiatus, Periopthalmus mallacensis, dan Periophthalmodon septemradiatus dengan ciri diagnostik bagian frenum yang berbeda di antara spesies, pola warna, jumlah jari-jari sirip dorsal pertama dan kedua serta 23 karakter morfometrik.
\end{abstract}

Kata kunci: Identifikasi, ikan Mudskipper, morfometrik, meristrik

\section{Identification of Mudskipper Species in Surabaya and Sidoarjo Beach}

\author{
Anisya Eka Juniar ${ }^{1)}$, Syefrina Rosyada'), Ahnan Mahfudz Nur S1), Dwi Anggorowati Rahayu ${ }^{1 *}$ \\ ${ }^{1}$ Biology Department, Faculty of Mathematics and Natural Sciences, Universitas Negeri Surabaya, Indonesia \\ ${ }^{*)}$ Email: dwirahayu@unesa.ac.id
}

\begin{abstract}
Mudskipper fish is included in the Gobiidae family, which can adapt to two different habitats. The existence of this fish is very abundant in nature, however, it is unknown to people for their existence. The purpose of this study was identified Mudskipper fish species in Kenjeran Beach, Mangrove Wonorejo Pond, and Sedati Pond so, it becomes additional information in terms of taxonomic and ecological aspects as a basis for management and benefaction. The method was used in this research using sweeping locations for fish sampling in three different locations and identification using morphological characters, which were morphometrics, meristic and diagnostic to determinate of species. The results of this study found four species of Mudskipper fish from three different locations, namely Boleophthalmus boddarti, Periopthalmus novemradiatus, Periopthalmus mallacensis, and Periophthalmodon septemradiatus with diagnostic characters of the frenum which different between species, color patterns, number of first and second dorsal fin rays and 23 morphometric characters.
\end{abstract}

Keywords: identification, Mudskipper, morphometric, meristrics

\section{PENDAHULUAN}

Indonesia terletak di antara Samudera Hindia dan Pasifik sehingga menyebabkan kondisi yang baik untuk perkembangbiakan ikan. Indonesia merupakan wilayah perairan tropis yang terkenal kaya dalam keragaman jenis ikan $[1,2]$. Laut Jawa merupakan bagian dari Paparan Sunda yang seluruhnya merupakan perairan teritorial dengan kedalaman maksimal 70 meter [3]. Wilayah Jawa Timur terletak pada $111,1^{\circ}-114,4^{\circ}$ Bujur Timur dan $7,12^{\circ}-8,48^{\circ}$ Lintang Selatan, sedangkan secara geografis Jawa Timur terletak di ujung timur Pulau Jawa. 
Bentang alam tersebut menyebabkan melimpahnya jenis ikan di wilayah Jawa Timur, salah satunya ialah ikan daerah tidal yaitu ikan Mudskipper.

Ikan Mudskipper termasuk salah satu ikan yang melimpah di alam. Ikan ini termasuk dalam Famili Gobiidae dan Subfamili Oxudercinae [4]. Ikan ini merupakan salah satu jenis ikan yang memiliki adaptasi terhadap dua habitat berbeda, yaitu daratan dan perairan. Ikan Mudskipper memiliki beragam jenis namun memiliki banyak kesamaan secara morfologi [5]. Menurut AlBehbehani \& Ebrahim [6] ikan Mudskipper mampu bertahan di daerah pasang surut karena memiliki kemampuan bernafas melalui kulit tubuhnya dan lapisan selaput lendir di mulut serta kerongkongannya.

Identifikasi ikan Mudskipper dapat dilakukan dengan menggunakan karakter morfologi. Hasil penelitian Ramadhani [7] menyebutkan bahwa ikan Mudskipper di kawasan pesisir Brebes ditemukan enam jenis ikan Mudskipper di antaranya Acentrogobius viridispunctatus, Boleophthalmus pectinirostris, Oxuderces nexipinnis, Parapocryptes serperaster, Periophtalmodon schlosseri, dan Scartelaos histophorussetiap. Setiap jenis ikan Mudskipper memiliki karakter morfologi yang berbeda. Karakter morfologi meliputi studi morfometrik, meristik dan karakter khusus yang dimiliki oleh ikan. Morfometrik memiliki arti sebagai ciri yang berkaitan dengan ukuran tubuh atau bagian tubuh ikan misalnya panjang total dan panjang baku ikan secara khusus. Parameter ukuran tubuh atau bagian tubuh ikan tersebut, merupakan salah satu hal yang dapat digunakan sebagai ciri taksonomik saat mengidentifikasi ikan, sedangkan karakter meristik adalah ciri yang berkaitan dengan jumlah bagian tubuh dari ikan, misalnya jumlah sisik pada garis rusuk, jumlah jari-jari keras dan lemah pada sirip punggung [1].

Keberadaan ikan Mudskipper di lingkungan memiliki peran untuk mengatasi perubahan suhu lingkungan yang ekstrim [8]. Informasi jenis mengenai ikan Mudskipper telah banyak dilakukan, namun di Jawa Timur masih sangat sedikit informasi terkait identifikasi jenis ikan Mudskipper. Distribusi keberadaan ikan Mudskipper di Indonesia banyak terdapat di Bangka, Sumatera (Aceh, Belawan), Jawa (Jakarta, Semarang), Madura (Kamal, Sumenep), Kalimantan (Pamangkat, Singkawang, Sungai Duri, Banjarmasin, Samarinda, Sambas, Tarakan) dan Sulawesi
(Makassar) [11]. Pada penelitian ini akan memberikan informasi lebih lanjut terkait jenis ikan Mudskipper di Jawa Timur.

\section{METODE PENELITIAN}

Penelitian yang dilaksanakan merupakan penelitian deskriptif kuantitatif. Metode yang digunakan ialah dengan melakukan Penyisiran lokasi. Penyisiran lokasi pengambilan sampel ikan Mudskipper (Gobiidae: Oxudercinae) dilakukan di kawasan hutan mangrove Wonorejo, Pesisir Pantai Kenjeran, dan Tambak Sedati. Identifikasi jenis menggunakan buku identifikasi oleh Weber [9] dan Murdy [10].

Pengambilan sampel. Pengambilan sampel ikan Mudskipper terdiri dari observasi lokasi penelitian dan pengambilan sampel ikan Mudskipper dengan melakukan penyisiran lokasi. Pengukuran ekologi dilakukan sebagai data habitat ikan Mudskipper di lingkungan. Pengamatan sampel ikan Mudskipper terdiri dari identifikasi morfologi ikan dengan melakukan pengamatan dan pengukuran pada 23 karakter morfometrik dan pengamatan meristrik yang meliputi jumlah jari-jari sirip (D), anal (A), pectoral $(\mathrm{P})$, caudal $(\mathrm{C})$, ventral $(\mathrm{V})$, jumlah sisik lateral, jumlah sisik tranversalis, dan jumlah sisik predorsal (Gambar 1).

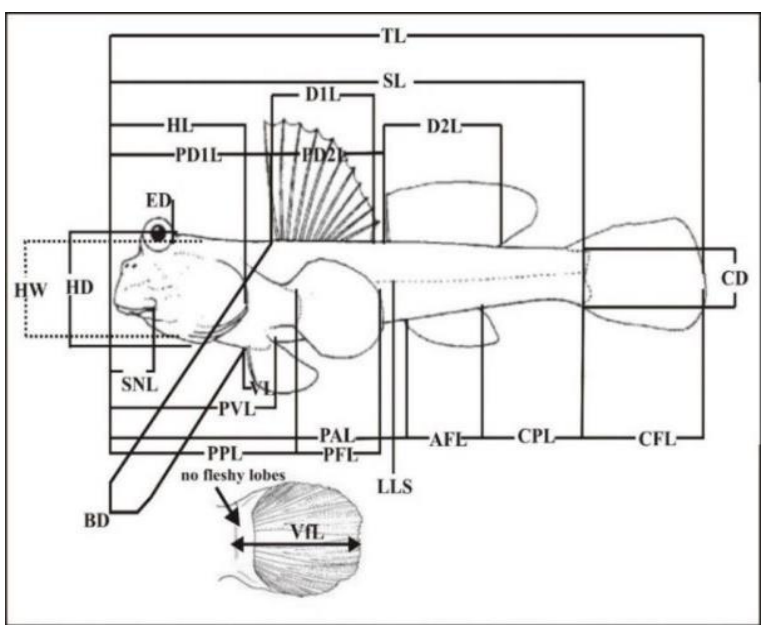

Gambar 1. Karakter morfometrik yang diukur [4]

Analisis Data. Analisis data dilakukan dengan menghitung rata-rata dan standar deviasi dengan memasukkan data perhitungan morfologi ikan menggunakan Ms. Excel dan diagnostik meristrik untuk mengetahui jenis kelompok ikan Mudskipper yang ditemukan. 


\section{HASIL DAN PEMBAHASAN}

\section{Identifikasi Ikan Mudskipper yang}

ditemukan. Pada penelitian ini, ikan Mudskipper yang ditemukan pada habitat Pantai Kenjeran, tambak mangrove Wonorejo dan
Tambak Sedati sebanyak empat spesies yaitu Boleophthalmus boddarti, Periopthalmus novemradiatus, Periopthalmus mallacensis, dan Periophthalmodon septemradiatus. Berikut ini deskripsi karakter ikan Mudskipper yang ditemukan pada lokasi penelitian.

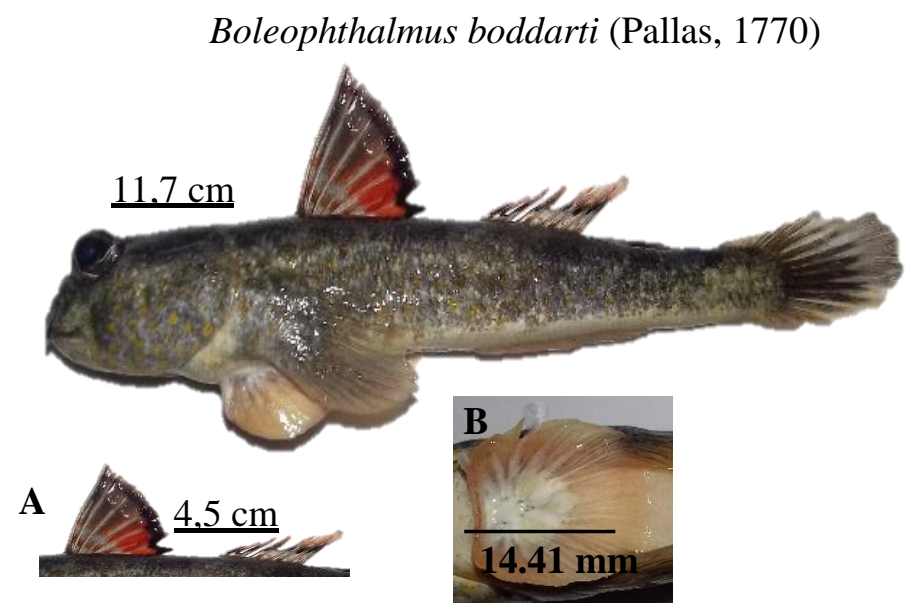

Gambar 2. Boleopthalmus boddarti, $\mathrm{SL}=9,3 \mathrm{~cm}$, Pantai Kenjeran Surabaya Jawa Timur. A. Jari-jari sirip dorsal pertama dan kedua, B. Sirip ventral frenum.

Karakteristik: Jari-jari sirip dorsal lebih pendek daripada jari-jari sirip dorsal ke-2. Jumlah jari-jari sirip dorsal $\mathrm{D}^{1} \mathrm{VIII}, \mathrm{D}^{2} 8$, jumlah jari-jari sirip pektoral P16, jumlah jari-jari sirip anal A11, jumlah jari-jari sirip caudal C21 serta jumlah jari-jari sirip ventral V14. Jumlah sisik longitudinal SS $\mathrm{L}=40$, jumlah sisik ventral $\mathrm{SS}$ $\mathrm{V}=11$, dan jumlah sisik pre dorsal $\mathrm{SS} \mathrm{P}=19$, sirip ventral menyatu dengan frenum menonjol.

Pola Warna: Warna tubuh abu-abu kecoklatan. Warna sirip dorsal coklat sedikit merah dengan beberapa spot putih pada jari-jari sirip, warna jari-jari sirip dorsal hitam dengan sekat putih. Bagian ventral tubuh berwarna putih pucat. Terdapat spot kuning pada bagian kepala dan ventral tubuh. Distribusi: India, Burma, Thailand, Vietnam dan Singapura [10]; Sumatra dan Borneo [11]; Lombok [12]; dan Tarakan (Kalimantan Utara) [4]; Surabaya (Pantai Kenjeran).

\section{Periopthalmus novemradiatus}

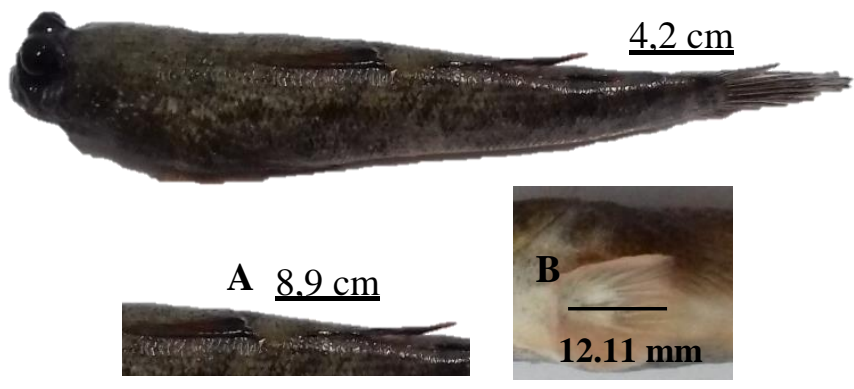

Gambar 3. Periopthalmus novemradiatus, $\mathrm{SL}=7,1 \mathrm{~cm}$, Tambak Sedati Sidoarjo Jawa Timur. A. Jari-jari sirip dorsal pertama dan ke-2, B. Sirip ventral frenum.

Karakteristik: Jari-jari sirip dorsal pertama lebih pendek daripada jari-jari sirip dorsal kedua. Jumlah jari-jari sirip dorsal $\mathrm{D}^{1} \mathrm{VI}, \mathrm{D}^{2} 12$, jumlah jari-jari sirip pectoral $\mathrm{P} 19$, jumlah jari- 
jari sirip anal A8, jumlah jari-jari sirip caudal C15 serta jumlah jari-jari sirip ventral V14. Jumlah sisik longitudinal SS L=32, jumlah sisik ventral SS V=16, dan jumlah sisik pre dorsal SS $\mathrm{P}=16$. Sirip pelvic memiliki frenum tanpa lubang. Antara jari-jari sirip pertama dorsal dengan jari-jari sirip ke-2 tidak dihubungkan oleh selaput membran.

Pola Warna: Warna tubuh hitam kecoklatan.

Warna sirip dorsal hitam sedikit coklat. Warna

\section{Periopthalmus mallacensis}

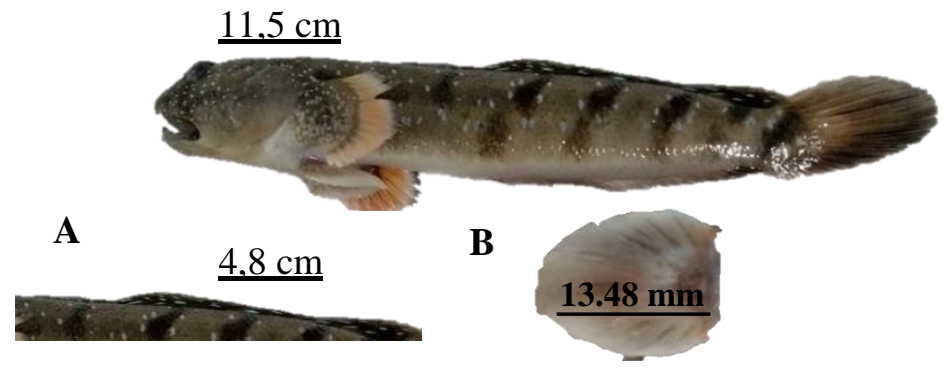

Gambar 4. Periopthalmus novemradiatus, $\mathrm{SL}=9,1 \mathrm{~cm}$, Tambak Sedati Sidoarjo Jawa Timur.A. Jari-jari sirip dorsal pertama dan ke-2, B. Sirip ventral frenum.

Karakteristik: Jari-jari sirip dorsal pertama lebih panjang daripada jari-jari sirip dorsal ke-2. Jumlah jari-jari sirip dorsal $\mathrm{D}^{1} \mathrm{IV}, \mathrm{D}^{2} 25$, jumlah jari-jari sirip pectoral $\mathrm{P} 16$, jumlah jari-jari sirip anal A21, jumlah jari-jari sirip caudal C16 serta jumlah jari-jari sirip ventral $\mathrm{V} 11$. Jumlah sisik longitudinal SS $\mathrm{L}=26$, jumlah sisik ventral $\mathrm{SS}$ $\mathrm{V}=21$, dan jumlah sisik pre dorsal $\mathrm{SS} \mathrm{P}=18$. Sirip ventral versatu dengan karakteristik frenum menonjol. Bagian ujung jari-jari sirip membulat, jari-jari pertama sirip dorsal pertama memanjang, sirip dorsal tidak dihubungkan oleh membran.
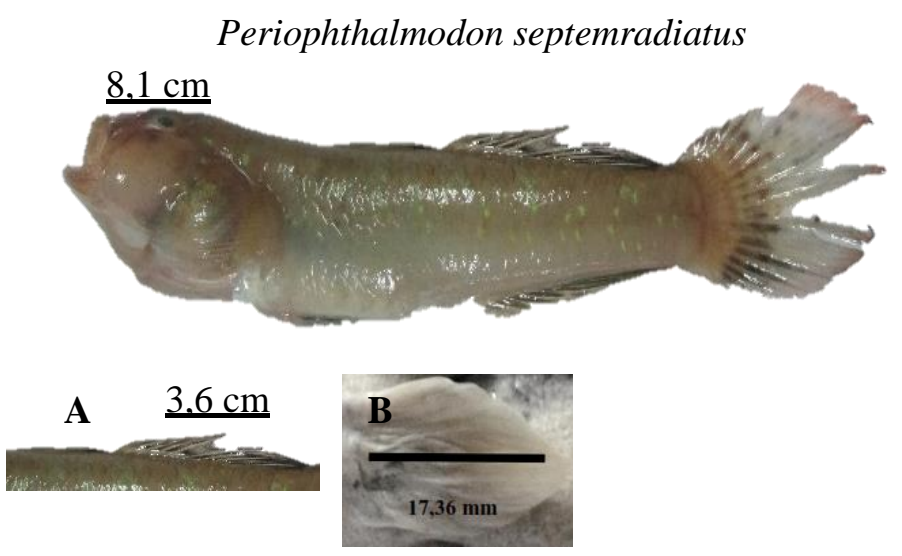

Gambar 5. Periopthalmus septemradiatus, $\mathrm{SL}=6,7 \mathrm{~cm}$, Tambak Sedati Sidoarjo Jawa Timur. A. Jari-jari sirip dorsal pertama dan ke-2, B. Sirip ventral frenum.
Pola Warna: Warna tubuh coklat kehitaman dengan spot putih bagian anterior dan posterior tubuh. Warna sirip dorsal coklat dengan sedikit hitam. Warna jari-jari sirip dorsal coklat dengan sekat putih. Bagian ventral tubuh berwarna putih pucat kecoklatan. Warna coklat kehitaman dengan spot bintik putih pada bagian kepala.

Distribusi: Filipina, Singapura, Lombok dan Tarakan (Kalimantan Utara) [4]; Tambak Sedati Sidoarjo. 
Karakteristik: Jari-jari sirip dorsal pertama lebih pendek daripada jari-jari sirip dorsal ke-2. Jumlah jari-jari sirip dorsal $\mathrm{D}^{1} \mathrm{~V}, \mathrm{D}^{2} 11$, jumlah jari-jari sirip pectoral $\mathrm{P} 10$, jumlah jari-jari sirip anal A7, jumlah jari-jari sirip caudal C21 serta jumlah jari-jari sirip ventral V10. Jumlah sisik longitudinal SS $\mathrm{L}=18$, jumlah sisik ventral $\mathrm{SS}$ $\mathrm{V}=22$, dan jumlah sisik pre dorsal $\mathrm{SS} \mathrm{P}=20$ dan jumlah sisik pre dorsal 16. Antara jari-jari pertama sirip dorsal dan jari-jari ke-2 sirip dorsal tidak dihubungkan oleh selaput membran. Jarak awal sirip anal lebih awal daripada jarak awal sirip dorsal ke-2.

Pola Warna: Warna tubuh abu-abu kecoklatan terdapat sedikit warna jingga pada bagian anterior dan posterior tubuh. Warna sirip dorsal abu-abu kecoklatan. Warna jari - jari sirip dorsal coklat dengan sekat putih. Bagian ventral tubuh berwarna putih pucat. Warna abu-abu kecoklatan.

Distribusi: Lombok [11]. Tambak Sedati Sidoarjo.

Menurut Anggara [14] diperoleh hasil penelitian yang telah dilakukan di Muara Porong ditemukan sebanyak tiga jenis ikan Mudskipper yaitu Boleophthalmus pectinirostris, Boleophthalmus boddarti, dan Periophthalmodon schlosseri. Selain itu, Soetjipto [15] menyatakan bahwa komunitas di lingkungan yang berlainan akan memperlihatkan perbedaan dalam keragaman spesies yang dikandungnya.

\section{Pengamatan Ikan Mudskipper} Berdasarkan Karakter Morfometrik. Analisis lebih lanjut untuk memperkuat status taksonomi ikan Mudskipper yang ditemukan di tiga lokasi berbeda dilakukan dengan pengukuran karakter morfometrik dengan menggunakan 23 karakter, di antaranya ukuran panjang sirip ventral yang merupakan pembeda utama spesies di antara golongan ikan Mudskipper. Data pengukuran karakter morfometrik dilihat pada Tabel 1.

Berdasarkan analisis tabel karakter morfometrik ikan Mudskipper dengan 23 karakter diperoleh perbedaan ukuran (panjang) dari masing-masing karakter pada setiap individu spesies yang ditemukan. Kisaran panjang standar spesies Baleopthalmus boddarti (91,2 $\pm 0,89 \mathrm{~mm})$, Perioptalmus novemradiatus $(68,9 \pm 0,21 \mathrm{~mm})$, Perioptalmus mallacencis $(9,0 \pm 0,9 \mathrm{~mm})$, dan Periopthalmodon septemradiatus $(66,5 \pm 0,21 \mathrm{~mm})$. Berdasarkan rentang kisaran panjang standar tersebut maka dapat diperoleh karakter morfometrik yang sesuai.

Tabel 1. Karakter morfometrik ikan Mudskipper

\begin{tabular}{|c|c|c|c|c|c|}
\hline No & $\begin{array}{l}\text { Karakter } \\
\text { Morfometri } \\
\mathrm{k}\end{array}$ & $\begin{array}{c}\text { Spesie } \\
\text { s I } \\
(\mathrm{cm}) \\
\end{array}$ & $\begin{array}{c}\text { Spesie } \\
\text { S II } \\
(\mathrm{cm}) \\
\end{array}$ & $\begin{array}{c}\text { Spesie } \\
\text { S III } \\
(\mathrm{cm}) \\
\end{array}$ & $\begin{array}{c}\text { Spesie } \\
\text { s IV } \\
(\mathrm{cm}) \\
\end{array}$ \\
\hline 1. & $\mathrm{TL}$ & 0.141 & 0.636 & 0 & 0.212 \\
\hline 2. & SL & 0.212 & 0.212 & 0.141 & 0.071 \\
\hline 3. & HL & 0 & 0.141 & 0.071 & 0.141 \\
\hline 4. & PD1L & 0.141 & 0 & 0.071 & 0.141 \\
\hline 5. & PD2L & 0.071 & 0.212 & 0.071 & 0 \\
\hline 6. & D1L & 0.141 & 0.283 & 0.424 & 0.424 \\
\hline 7. & D2L & 0 & 0.849 & 0.071 & 0.071 \\
\hline 8. & CD & 0.071 & 0.071 & 0.141 & 0.141 \\
\hline 9. & CFL & 0.071 & 0.212 & 0.071 & 0.071 \\
\hline 10. & CPL & 0.071 & 0.071 & 0.141 & 0.141 \\
\hline 11. & AFL & 0 & 0.212 & 0.212 & 0.141 \\
\hline 12. & LLS & 0.212 & 0.495 & 0.283 & 0,071 \\
\hline 13. & PAL & 0.354 & 0.071 & 0.141 & 0 \\
\hline 14. & PFL & 0.000 & 0 & 0.071 & 0.141 \\
\hline 15. & PPL & 0.424 & 0.283 & 0.212 & 0 \\
\hline 16. & ED & 0 & 0.071 & 0 & 0 \\
\hline 17. & HD & 0 & 0.141 & 0.283 & 0 \\
\hline 18. & SNL & 0.141 & 0 & 0.141 & 0.071 \\
\hline 19. & HW & 0.141 & 0.071 & 0.000 & 0 \\
\hline 20. & VL & 0 & 0.141 & 0.071 & 0 \\
\hline 21. & PVL & 0.141 & 0.141 & 0.071 & 0.141 \\
\hline 22. & $\mathrm{BD}$ & 0.283 & 0.354 & 0.000 & 0.212 \\
\hline 23. & VFL & 0.283 & 0.212 & 0.000 & 0.141 \\
\hline
\end{tabular}

Keterangan:

Spesies I: Boleopthalmus boddarti; Spesies II: Periopthalmus novemradiatus; Spesies III: Periopthalmus mallacensis; Spesies IV:

Periohthalmodon septemradiatus

Pengukuran morfometrik terhadap 23 karakter dapat memperkuat jenis spesies ikan Mudskipper yang ditemukan pada tiga lokasi tersebut serta dapat membedakan setiap individu antar jenis [16]. Hasil pengukuran karakter morfometrik merupakan salah satu acuan yang dapat digunakan sebagai ciri taksonomik saat mengidentifikasi ikan [1]. Nugroho dkk. [4] menyatakan bahwa setiap spesies mempunyai sebaran geografi tertentu yang dikontrol oleh kondisi fisik lingkungannya.

Pengukuran Habitat Ikan Mudskipper berdasarkan Ekologi. Kondisi ekologis ikan Mudskipper tersebut terlampir pada Tabel 2. 
Tabel 2. Hasil ekologi habitat ikan Mudskipper

\begin{tabular}{lccc}
\hline \multirow{2}{*}{ Parameter } & \multicolumn{3}{c}{ Stasiun Pengamatan } \\
\cline { 2 - 4 } & I & II & III \\
\hline pH air & & 6.5 & 6.5 \\
Suhu air ( & 33 & 26 & 26 \\
C) & & & \\
Salinitas (\%o) & 3 & 2 & 3.2 \\
\hline
\end{tabular}

\section{Keterangan:}

Stasiun I: Pantai Kenjeran; Stasiun II: Tambak Mangrove Wonorejo; Stasiun III: Tambak Sedati Sidoarjo

Berdasarkan hasil analisis Tabel 2. Pada ketiga stasiun diperoleh hasil nilai $\mathrm{pH}$ air sebesar 6,5 - 7. Romimohtarto (1991) menyatakan bahwa pH 6-9 merupakan kisaran yang dapat ditolerir bagi kehidupan organisme laut. Sehingga dapat diasumsikan bahwa perairan dari ketiga stasiun memiliki kisaran tolerir $\mathrm{pH}$ air dalam kehidupan ikan Mudskipper. Tinggi rendahnya keanekaragaman jenis ikan Mudskipper dipengaruhi oleh banyak faktor dan salah satu faktor adalah kualitas lingkungan. Gunarto [17] berpendapat bahwa daerah atau substrat lumpur merupakan habitat berbagai nekton, yang menandakan daerah tersebut kaya akan sumber pakan. Adanya variasi habitat (substrat), seperti kondisi fisik dan lingkungan sekitar memengaruhi keragaman jenis-jenis ikan $[13,18]$.

\section{KESIMPULAN}

Terdapat empat jenis ikan Mudskipper yang ditemukan di tiga lokasi pengamatan. Jenis yang ditemukan yaitu Boleopthalmus boddarti, Periopthalmus novemradiatus, Periopthalmus mallacensis, dan Periohthalmodon septemradiatus. Berdasarkan hasil penelitian terhadap morfometrik diperoleh hasil pengukuran panjang terhadap 23 karakter yang berbeda pada setiap individu antar spesies ikan Mudskipper.

\section{UCAPAN TERIMA KASIH}

Terima kasih kami ucapkan kepada Kemristekdikti yang telah memberikan pendanaan pada penelitian ini. Terima kasih pula kami sampaikan kepada Ibu Dwi Anggorowati Rahayu, S.Si. M.Si selaku dosen pembimbing dalam membimbing penelitian ini.

\section{DAFTAR PUSTAKA}

[1] Affandi R, Sjafei DS, Rahardjo MF,

Sulistiono (1992) Iktiologi. Suatu

Pedoman Kerja Laboratorium.

Departemen Pendidikan dan Kebudayaan.

Direktorat Jenderal Pendidikan Tinggi.

Pusat Antar Universitas Ilmu Hayat.

Institut Pertanian Bogor, Bogor.

[2] Dahuri M (2004) Peran IPTEK dan Agribisnis dalam Pemanfaatan dan Pengelolaan Sumberdaya Perikanan Indonesia. Makalah disampaikan pada Seminar Nasional Ikan Ke III. Bogor.

[3] Nurhakim S, Nikijuluw VPH, Nogroho D, Prisantoso BD (2007) Status Perikanan Menurut Wilayah Pengelolaan. Pusat Riset Perikanan Tangkap.

[4] Nugroho ED, Ibrahim, Rahayu DA, Rupa D (2016) Studi morfologi ikan Mudskipper (Gobiidae: Oxuddercinae) sebagai upaya karakterisasi biodiversitas lokal Pulau Tarakan. Jurnal Harpodon Borneo 9 (1): 46-57.

[5] Gosal LM, Katili DY, Singkoh MFO, Tamanampo J (2013) Kebiasaan makanan ikan Mudskipper (Periophthalmus sp.) di kawasan mangrove Pantai Meras, Kecamatan Bunaken, Kota Manado, Sulawesi Utara. Jurnal Bios Logos 3(2): 44-4.

[6] Al-Behbehani BE, Ebrahim HMA (2010) Enviromental studies on the Mudskippers in the intertidal zone of Kuwait Bay. Nature and Science 8 (5): 79-89.

[7] Ramadhani S, Setyobudhiandi I, Haryadi S (2018) Inventarisasi dan kologi ikan Gelodok (Famili: Gobidae) di Kabupaten Brebes Provinsi Jawa Tengah. Jurnal pengelolaan perikanan tropis 2(1): 43-51. doi: https://doi.org/10.29244/jppt,2,1,4351.

[8] Taylor JR, Cook MM, Kirkpatrick AL, Galleher SN, Eme J, Bennett WA (2005) Thermal tactics of air-breathing and non air-breathing Gobiids inhabiting mangrove tidepools on Palau Hoga, Indonesia. Copeia 2005: 885-892.

[9] Weber M, de Beaufort LF (1953) The fishes of Indo-Australian Archipelago. Vol. X Gobioidea. Leiden E.J. Brill. pp. 423.

[10] Murdy EO (1989) A taxonomic revision and cladistic analysis of the Oxudercine gobies (Gobiidae: 
Oxudercinae). Rec Aus Mus Suppl 11: 193

[11] Kottelat M, Anthony J, Sri NK, Soetikno W (1993). Freshwater fishes of Western Indonesia and Sulawesi. Jakarta. Periplus Edition

[12] Zamroni Y (2011) Morphological study of Goby (Gobiidae) from Lombok Island Indonesia. Sekolah Pasca Sarjana Bogor Agriculture University

[13] McManus, JW, Miclot RI, Salagano VT (1981) Coral and fish community structure of Somrero Island, Batanganos, Philippines, In Proceeding Fourth International Coral Reef Symposium, pp. 271-280.

[14] Anggara (2013) Studi populasi ikan Mudskipper (Oxudercinae) di Muara Sungai Porong, Desa Kedungpandan, Kecamatan Jabon, Kabupaten Sidoarjo. Thesis Sarjana. Universitas Brawijaya

[15] Soetjipto (1993) Dasar-dasar ekologi hewan. Departemen Pendidikan dan Kebudayaan Direktorat Jenderal Pendidikan Tinggi, Yogyakarta

[16] Whitten T, Damanik S, Anwar J, Hisyam N (2000) The ecology of Sumatra. Singapura, Periplus Edition

[17] Gunarto (2004) Konservasi mangrove sebagai pendukung sumber hayati perikanan pantai. Jurnal Litbang Pertanian 23 (1): 15-21.

[18] Yustina (2001) Keanekaragaman jenis ikan di sepanjang perairan Sungai Rangau, Riau Sumatera. J. Natur Indonesia 4:1-14 